$$
\begin{array}{r}
\text { Pontifícia Universidade C Católica } \\
\text { do Rio de Janeiro }
\end{array}
$$

Cecilia Caraciki Muruci Machado

Aposentadoria e o Trade-off entre Renda e Lazer: Implicações para o Valor do Capital Humano de Funcionários Públicos

Dissertação apresentada como requisito parcial para obtenção do título de Mestre pelo Programa de PósGraduação em Economia da PUC-Rio.

Orientador: Walter Novaes Co-orientador: José Márcio Camargo

Rio de Janeiro, março de 2005. 


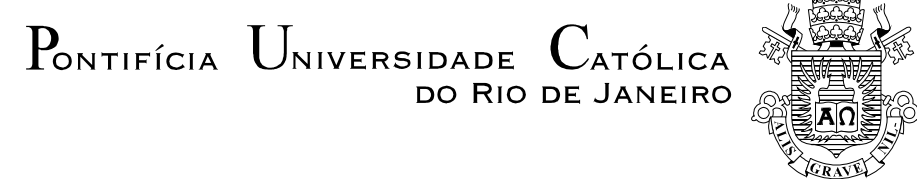

Cecilia Caraciki Muruci Machado

\title{
Aposentadoria e o Trade-off entre Renda e Lazer: Implicações para o Valor do Capital Humano de Funcionários Públicos
}

\begin{abstract}
Dissertação apresentada como requisito parcial para obtenção do título de Mestre pelo Programa de PósGraduação em Economia da PUC-Rio. Aprovada pela Comissão Examinadora abaixo assinada.
\end{abstract}

\author{
Walter Novaes \\ Orientador \\ PUC-Rio \\ José Márcio Camargo \\ Co-orientador \\ PUC-Rio \\ Juliano Junqueira Assunção \\ PUC-Rio \\ Luis Henrique Braido \\ FGV/EPGE
}

João Pontes Nogueira

Coordenador Setorial do Centro de Ciências Sociais - PUC-Rio

Rio de Janeiro, 11 de março de 2005. 
Todos os direitos reservados. É proibida a reprodução total ou parcial do trabalho sem autorização da universidade, da autora e do orientador.

\section{Cecilia Caraciki Muruci Machado}

Graduou-se em economia pela Universidade Federal do Rio de Janeiro.

Ficha Catalográfica

Machado, Cecilia Caraciki Muruci

Aposentadoria e o trade-off entre renda e lazer: implicações para o valor do capital humano de funcionários públicos / Cecilia Caraciki Muruci Machado ; orientadores: Walter Novaes, José Márcio Camargo. - Rio de Janeiro : PUC, Departamento de Economia, 2005.

69 f. ; $30 \mathrm{~cm}$

Dissertação (mestrado) - Pontifícia Universidade Católica do Rio de Janeiro, Departamento de Economia.

Inclui referências bibliográficas.

1. Economia - Teses. 2. Capital humano. 3. Mercado de trabalho no setor público. 4. Aposentadoria. I. Novaes, Walter. II. Camargo, José Márcio. III. Pontifícia Universidade Católica do Rio de Janeiro. Departamento de Economia. IV. Título. 


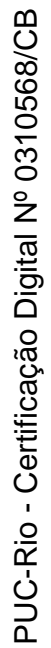

À minha família

Ao Tiago 


\section{Agradecimentos}

Aos meus pais, Carlos e Aline, e ao meu irmão, Lourenço, pelo apoio durante estes longos anos de estudo. Sem a paciência e o carinho de vocês, meu caminho teria sido bastante mais árido.

Ao meu querido Tiago, pelos comentários sempre pertinentes e pelo incentivo nos momentos mais difíceis. Pelo amor e compreensão de sempre, por me fazer sorrir.

Ao meu orientador, Walter Novaes, por todos os ensinamentos. Pela dedicação e disponibilidade, me fazendo descobrir os reais desafios de um pesquisador. Obrigada pelo exemplo e motivação.

Aos professores do departamento, em especial ao professor José Marcio Camargo, meu co-orientador neste trabalho, pelos frutíferos comentários nos workshops.

Aos meus colegas de turma no mestrado, pelos momentos de descontração sempre necessários. Meninos, o bom humor de vocês foi fundamental.

À Capes e ao CNPQ, pelos auxílios concedidos. 


\section{Resumo}

Machado, Cecilia Caraciki Muruci; Aposentadoria e o Trade-off entre Renda e Lazer: Implicações para o Valor do Capital Humano de Funcionários Públicos. Rio de Janeiro, 2005. 69p. Dissertação de Mestrado - Departamento de Economia, Pontifícia Universidade Católica do Rio de Janeiro.

Que se espera de um funcionário público que se aposenta ainda jovem: trabalhar ou usar o tempo livre para lazer? Caso trabalhe, então a reforma previdenciária de 1998 - que impôs idade mínima para aposentadoria - causa perda de renda futura que deve ser compensada por aumento de poupança corrente. Caso a opção seja por lazer, a reforma resulta em perda de lazer futuro, o que, sob a hipótese de complementaridade entre consumo e lazer, implica na realocação de consumo futuro para o presente, ou seja, decréscimo de poupança corrente. Usando uma amostra com dados da PNAD de 33.893 funcionários públicos, mostramos que, com a implementação da reforma, a poupança dos servidores civis caiu relativamente aos militares, que não foram atingidos pela reforma. Como as decisões de lazer e trabalho dependem do salário de mercado, o experimento sugere que o setor privado não dá um valor significativo para o capital humano dos servidores públicos.

\section{Palavras-chave}

capital humano; mercado de trabalho no setor público; aposentadoria 


\section{ABSTRACT}

Machado, Cecilia Caraciki Muruci; Retirement and the Leisure-Income Trade-off: Implications to the Human Capital Value of Public Sector Employees. Rio de Janeiro, 2005. 69p. MSc. Thesis - Departamento de Economia, Pontifícia Universidade Católica do Rio de Janeiro.

What should we expect from public employees that retire at early ages: continue working or enjoy full leisure time? If they continue working, the Brazilian 1998 pension reform - that established minimum retirement age for public employees - reduces future income and increases current savings, as consumption is smoothed through time. If the answer is leisure, the reform implies additional work and savings decrease in consequence of future consumption transfer to the present. This is the case of leisure and consumption being complements in the utility function. We use a sample with 33,893 public employees from the PNAD database (1996 to 2002) to show that there was a decrease in saving relative to the military, which were not affected by the reform. Since work and leisure decisions rely on the market alternative wage, this result suggests that the private sector does not greatly value the human capital of public employees.

\section{Keywords}

human capital; public sector labor markets; retirement 


\section{Sumário}

1 Introdução 10

2 Reforma Previdenciária e Impactos sobre a Poupança dos Funcionários Públicos

3 Dados e Modelo Econométrico 21

3.1. A amostra de funcionários públicos $\quad 21$

3.2. Grupo de controle e modelo econométrico 22

4 Estimando o Trade-off entre Renda e Lazer 27

5 Testes de Robustez 29

5.1. Teste para o modelo econométrico 30

5.1.1. Tendência 30

5.1.2. Incluindo outras variáveis de controle 31

5.2. Grupos de Controle 32

5.2.1. Outros grupos de controle 33

5.2.2. Propensity Score Matching 35

5.3. Interpretação da queda da poupança 36

5.3.1. Restrição ao crédito 36

5.3.2. Amplificando o efeito renda 37

5.3.3. Efeito da reforma sobre os indivíduos que não são

$\begin{array}{ll}\text { chefes de família } & 39\end{array}$

6 Conclusão $\quad 41$

7 Referências bibliográficas 43

8 Apêndice $\quad 44$ 


\section{Lista de tabelas}

Tabela 1 Modificações Introduzidas pela Emenda

Constitucional $n^{\circ} 20$ de 1998

Tabela 2 Estatísticas Descritivas: Funcionários Públicos

de 1996 a 2002

Tabela 3 Testes de Média e Proporção 49

Tabela 4 Probit Previdência Privada: Funcionários

Públicos Civis e Militares $\quad 50$

Tabela 5 Probit Previdência Privada: Funcionários Públicos

Civis e Militares (Tendência) 52

Tabela 6 Probit Previdência Privada: Funcionários Públicos

Civis e Militares (outros controles) 54

Tabela 7 Probit Previdência Privada: Funcionários Públicos

Civis e Trabalhadores Sem Carteira

Tabela 8 Probit Previdência Privada: Funcionários Públicos

Civis e Trabalhadores Com Carteira

Tabela 9 Probit Previdência Privada: Funcionários Públicos e

Trabalhadores Conta-Própria

60

Tabela 10 Propensity Score Matching Previdência Privada:

Funcionários Públicos Civis e Militares

62

Tabela 11 Probit Previdência Privada: Funcionários Públicos

Civis e Militares (Restrição ao Crédito)

64

Tabela 12 Probit Previdência Privada: Funcionários Públicos

Civis e Militares (Renda versus Lazer)

66

Tabela 13 Probit Previdência Privada: Funcionários Públicos

Civis e Militares (não chefes de família) 